\title{
Podostemaceae endémicas del Perú
}

Blanca León ${ }^{1,2}$

${ }^{1}$ Museo de Historia Natural, Av. Arenales 1256, Aptdo. 14-0434, Lima 14, Perú

2 Plant Resources Center, University of Texas at Austin, Austin TX 78712 EE.UU.

blanca.leon@mail.utexas.edu

\section{Resumen}

La familia Podostemaceae es reconocida en el Perú por presentar dos géneros y dos especies (Brako \& Zarucchi, 1993), ambas hierbas acuáticas. En este trabajo reconocemos estas dos especies como endémicas, las cuales han sido encontradas en las regiones Bosques Muy Húmedos Montanos y Matorral Desértico, entre los 1000 y 2000 m de altitud. Ninguna de las especies está representada dentro del Sistema Nacional de Áreas Naturales Protegidas por el Estado.

Palabras claves: Podostemaceae, Perú, endemismo, plantas endémicas.

\section{Abstract}

The Podostemaceae are represented in Peru by two genera and two species (Brako \& Zarucchi, 1993), both aquatic herbs. Here we recognize these two species as endemics, which are found in the Very Humid Montane Forests and Desert Shrubland regions, between 1000 and $2000 \mathrm{~m}$ elevation. Neither of these endemic species has been recorded in the Peruvian System of Protected Natural Areas.

Keywords: Podostemaceae, Peru, endemism, endemic plants.

\section{Apinagia peruviana Wedd. ex Engl.}

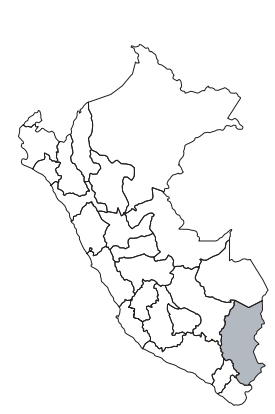

$$
\text { CR, B1a+b(iii) }
$$

Publicación: Nat. Pflanzenfam. (ed.2) 18a: 38. 1930

Colección tipo: A. Weddel s.n.

Herbarios: B.

Nombre común: Desconocido.

Registro departamental: PU.

Regiones Ecológicas: BMHP; altitud desconocida.

SINANPE: Sin registro.

Herbarios peruanos: Ninguno.

Observaciones: Esta especie herbácea, estrictamente acuática, se conoce sólo de la colección tipo, una planta recolectada en la cuenca del San Gabán,en el siglo XIX. Su hábitat, en ríos torrentosos, puede contribuir a la falta de registro en otras localidades. Philbrick \& Novelo (1995) comentaron sobre la presencia de alto endemismo en la familia; en el Perú, las dos especies de la familia son endémicas y al igual que México la escasez de colecciones dificulta conocer el rango exacto de distribución. De preocupación está que los ríos, en ambas vertientes de los Andes, están en su mayoría contaminados por la minería, y en el caso de San Gabán, empleado para generar energía eléctrica.

\section{Marathrum striatifolium P. Royen}

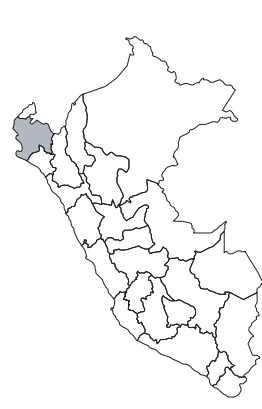

CR, B1a+b(iii)

Publicación: Meded. Bot. Mus. Herb. Rijks Univ. Utrecht 107: 87-88, 132-133, pl. 7, figs. 29-34. 1951.

Colección tipo: A. Weberbauer 6426

Herbarios: GH, US.

Nombre común: Desconocido.

Registro departamental: PI.

Regiones Ecológicas: MDE; 1000—2000 m.

SINANPE: Sin registro.

Herbarios peruanos: Ninguno.

Observaciones: Hierba acuática, conocida de una sola colección en el noroeste del Perú. Si bien el ejemplar de Weberbauer no incluye datos de altitud, sí los tiene de la localidad «abajo de Frías», por lo que corresponde a la región ecológica considerada aquí. Los ríos en la localidad tipo están sujetos a contaminación por actividad minera y probablemente afectadas por eventos El Niño. 